Manuscript accepted for publication in Social Networks 51, October 2017, pp. 104-117, special issue on Crime and Security Networks, doi: 10.1016/j.socnet.2017.03.012

\title{
The determinants of heroin flows in Europe: A latent space approach
}

\author{
Giulia Berlusconi, ${ }^{1 *}$ Alberto Aziani, ${ }^{2}$ Luca Giommoni ${ }^{3}$
}

\begin{abstract}
This study utilises recent advances in statistical models for social networks to identify the factors shaping heroin trafficking in relation to European countries. First, it estimates the size of the heroin flows among a network of 61 countries, before subsequently using a latent space approach to model the presence of trafficking and the amount of heroin traded between any two given countries. Many networks, such as trade networks, are intrinsically weighted, and ignoring edge weights results in a loss of relevant information. Traditionally, the gravity model has been used to predict legal trade flows, assuming conditional independence among observations. More recently, latent space position models for social networks have been used to analyze legal trade among countries, and, mutatis mutandis, can be applied to the context of illegal trade to count both edge weights and conditional dependence among observations. These models allow for a better understanding of the generative processes and potential evolution of heroin trafficking routes. This study shows that geographical and social proximity provide fertile ground for the formation of heroin flows. Opportunities are also a driver of drug flows towards countries where regulation of corruption is weak.
\end{abstract}

\section{Highlights}

- Directed, weighted network of bilateral heroin trade to and within Europe.

- Use of latent space position models to identify the determinants of heroin trade.

- Geographical and social proximity facilitates bilateral heroin trade.

- Heroin flows towards countries with weak regulation of corruption.

Keywords Heroin Trafficking; Latent space; Gravity model; Social proximity.

\section{Introduction}

Transnational drug trafficking is an illicit activity that involves exchanges between actors in different countries (Naylor, 2003; Paoli et al., 2009). As such, international drug flows can be analyzed in terms of a network of economic relationships between countries; hence, models designed for bilateral legal trade can be adapted to identify their determinants. Previous studies have documented how drug trafficking is concentrated within a limited number of particular routes, and that countries thus have a limited number of trading partners compared to legal trade networks (Boivin, 2013, 2014a; EMCDDA and EUROPOL, 2013; UNODC, 2015a). However, there is a relative dearth of information concerning the determinants of the routes used to supply drugs to the European markets.

\footnotetext{
${ }^{1}$ National University of Ireland, Maynooth, Ireland

${ }^{2}$ Università Cattolica del Sacro Cuore and Transcrime, Milan, Italy

${ }^{3}$ Cardiff University, School of Social Sciences, UK

* E-mail: giulia.berlusconi@ nuim.ie

(C) 2017. This manuscript version is made available under the CC-BY-NC-ND 4.0 license http://creativecommons.org/licenses/by-nc-nd/4.0/
} 
This study addresses the lacunae in extant research by identifying the determinants of heroin flows to and within Europe. It estimates the amount of heroin trafficked between European countries and nonEuropean countries importing from or exporting to Europe. Finally, through recourse to criminological and economic theories the study identifies the factors that may influence heroin trafficking, before adopting a latent space approach to model both the presence and the amount of heroin flows between countries. Analysing international heroin trade as a directed, weighted network represents a more accurate description of the complexity of the phenomenon than its binary counterparts (Boivin, 2014b; Chandra and Joba, 2015).

The article is structured as follows. The next section reviews extant literature on drug trafficking networks. The third section discusses the respective options for modelling illicit flows between countries. The fourth section presents the manifold factors underpinning international drug trafficking, and outlines the theoretical framework adopted in the study. The fifth section introduces the data and the methodology before presenting the main results in the penultimate section. The final section provides a conclusion and recommendations for policy makers.

\section{Background}

International drug trafficking generates considerable profits and represents one of the primary sources of income for criminal organizations. For example, the United Nations Office on Drug and Crime (UNODC) estimates that cross-national trafficking of heroin along the Balkan route solely is worth between USD 6.7 and 10 billion (UNODC, 2015b). The estimate rises to USD 28 billion per annum when consumption and production are included, and is exponentially higher yet still if drug-related expenditure is added up (e.g. health costs, enforcement costs). Indeed, heroin consumption continues to account for a substantive share of drug-related health and social costs in Europe (EMCDDA, 2015a), with the number of overdose deaths recently increasing along with the purity of heroin available in European markets (EMCDDA, 2015a), which goes some way to explaining why heroin is considered the most harmful illicit psychoactive substance in Europe (van Amsterdam et al., 2015).

Despite the magnitude of the problem, and the undoubted interest of practitioners and scholars, there remains little systematic research on drug flows between countries. Historically, the lack of data has been the principal factor hindering quantitative studies in this field. However, over the course of the last decade governments and international institutions have collected and provided a considerable amount of data on international drug trafficking, such as wholesale prices, seizures and purity (Chandra and Joba, 2015). These datasets constitute an unprecedented source of information that scholars have begun to use for the purposes of understanding how illicit drugs move across countries.

Data on drug flows are relational in nature, and, as such, are well suited for applying social network analysis methods (Boivin, 2013). Having said this, hitherto only a small amount of recent studies have adopted a network approach to analyze drug trafficking flows between countries (Boivin, 2014a, 2014b, 2013; Chandra and Joba, 2015; Giommoni et al., 2017). This is emblematic of both the recent availability of data, and criminologists' emergent interest in social network analysis methods to analyze the properties of illicit networks, including drug trade networks (see Carrington, 2011; Bouchard and Malm, 2016 for a review).

Thus far, the literature has provided two key contributions to the network analysis of international drug trafficking. The first contribution derives from a series of papers by Boivin (2014a, 2013), who uses macrosocial network analysis to both identify the role of countries with respect to drug flows, and 
to understand the structural properties of heroin, cocaine and cannabis trafficking networks. Boivin's (2013, 2014a) analysis of the networks - originally developed from data on seizures between 1998 and 2007- provides two main findings. First, that the trafficking of illicit drugs has a more ad hoc structure in comparison with the trade of legal commodities (e.g. coffee and chocolate). Second, that core countries within the legal economy tend to occupy peripheral positions within the international trade of illicit drugs. In a further paper, Boivin (2014b) analyses the wholesale prices of cocaine, heroin, and cannabis in an attempt to explain price mark-ups. OLS regression models were used to test the influence of country-level variables (e.g. level of corruption, flow betweenness score) and relational variables (e.g. geographical distance, direction of trade) on price mark-ups between any two given countries. The results show that some characteristics of the importer (e.g. risk of arrest), when viewed in conjunction with the position of the country within the global trafficking network, can predict wholesale price markups (Boivin, 2014b).

Chandra and colleagues provide the second key contribution to the network analysis of drug trafficking flows (Chandra et al., 2011; Chandra and Barkell, 2012; Chandra and Joba, 2015; Chandra et al., 2016). The authors use wholesale prices reported by the UNODC between 2000 and 2008 to infer the presence and direction of transnational flows of heroin (Chandra and Barkell, 2012) and cocaine (Chandra et al., 2011) for seventeen western European countries. The results of the analysis are mobilized to build two directed, binary networks of the international trafficking of heroin and cocaine in Europe (Chandra and Joba, 2015). The overlap between the two networks is limited, most likely due to differences in the geographical location of cocaine and heroin producing countries. For instance, the heroin trade network has more redundant ties and is more diffused than the cocaine network, leading the authors to conclude that it may be more resilient to interventions geared towards reducing the supply (Chandra and Joba, 2015). Recently, Chandra et al. (2016) used the same method to document trafficking patterns using MDMA wholesale prices in 59 US cities, identifying, in particular, the key role of border and coastal cities in this illegal market. This study is especially relevant as it focuses on cities, rather than countries, as nodes in a drug trafficking network.

The studies summarized above share a common feature: they analyze networks with binary flow data, i.e. networks that report information on whether the drug flows between any two given countries are present or absent. A recent study on the supply of heroin to Europe also analyzed trading relationships between countries in terms of binary network ties, using Exponential Random Graph Models (ERGM) to identify the determinants of drug routes (Giommoni et al., 2016). There are two primary justifications for excluding edge weights from the network analysis of drug trade networks. First, the inclusion of information on quantities of drugs traded between any two countries entails estimating the scale of illicit drug markets. This is not a straightforward endeavor, especially if the focus is on more than one country (Kilmer et al., 2015, 2011). Second, most statistical models for networks do not allow for the inclusion of edge weights in the analysis (e.g. Caimo and Friel, 2014; Hunter et al., 2008). However, illicit trafficking networks are intrinsically weighted, and, thus, ignoring edge weights may result in a loss of relevant information (Newman, 2004).

The studies adopting a network approach to the analysis of international drug trafficking proffer several insights about the phenomenon, but they are largely descriptive in nature. For example, they provide an account of the structure of the networks of international trafficking of heroin, cocaine and cannabis (e.g. density, countries' centrality), but fail to explain what shapes and drives the flows of illicit drugs between countries. Gravity-type models and, more recently, latent space position models have been introduced to test theories on bilateral trade and can be applied to directed, weighted networks representing cross-country illicit activities, including international drug trafficking. 


\section{Models for illicit trade networks: gravity and latent space position models}

Over the course of the last decade, social network analysis has proven its expedience for both refining criminological concepts and theories, and assisting law enforcement agencies in enforcing and preventing crime. That said, most research is descriptive in nature and focuses on the influence of personal and neighborhood networks on crime, and on the organization of criminal groups (see Calderoni, 2014; Carrington, 2011; Haynie and Soller, 2014; Papachristos, 2014 for a review). Illicit activities often involve the smuggling of goods or persons across countries. Human trafficking and smuggling, illicit firearms trafficking, trade-based money laundering are all archetypal examples of cross-country illicit activities that can be analyzed as networks (e.g. Ferwerda et al., 2011; Hernandez and Rudolph, 2015). As with drug trafficking, issues with the uniformity of available data has limited quantitative studies on these cross-country illicit activities. When such information is readily available, the determinants of illicit flows are identified using the same estimation strategies used for bilateral legal trade, i.e. gravity-type models (Akee et al., 2014; Ferwerda et al., 2011; Hernandez and Rudolph, 2015; Wiseman and Walker, 2017).

The gravity model postulates that the amount of traded goods and services moving between any two countries is proportional to the product of their size (or economic mass) divided by their geographical distance, with a country's size ordinarily being measured in terms of their gross domestic product (GDP) or market capitalization (Feenstra et al., 2001; Head and Mayer, 2014; Linnemann, 1966; Pöyhönen, 1963). The gravity model was first developed by Savage and Deutsch (1960), who put forward a model to understand transaction flows, using data on bilateral trade to demonstrate its application. The first empirical study was published two years later, when Tinbergen (1962) modelled bilateral trade flows so as to analyze international trade between 42 countries. Other covariates were subsequently added to the model (e.g. dummy variables for neighboring countries) without reducing the explanatory power of the main variables (i.e. size and distance). The gravity model also demonstrated its explanatory power in the case of trade flows at a subnational level; McCallum (1995), for example, found that the exchange of commodities between any two provinces and states of the US and Canada is proportional to their size and distance, and is influenced by whether they share a border.

In the case of studies on bilateral trade, the gravity model is usually estimated in terms of natural logarithms, and takes the following form:

$$
\ln \left(\operatorname{trade}_{i, j}\right)=\beta_{0}+\beta_{1} \ln M_{i}+\beta_{2} \ln M_{j}+\beta_{3} \ln D_{i, j}+\beta_{4} \ln Z_{i, j}+\epsilon_{i, j}
$$

where $\beta_{n}$ are the parameter estimates, $M_{i}$ and $M_{j}$ are the respective sender and receiver economic masses, $D_{i, j}$ the distance between $i$ and $j, Z_{i, j}$ other covariates, and $\epsilon_{i, j}$ the residual error. $\beta_{1}$ and $\beta_{2}$ are expected to be greater than zero, whereas $\beta_{3}$ is expected to be lower than zero (Ward and Hoff, 2007).

The coefficient of distance has traditionally been applied as a proxy for transaction costs. More specifically, some authors have posited that distance represents informational asymmetry between any two given countries, which, in turn, increases transaction costs (Portes et al., 2001; Portes and Rey, 2005). Indeed, when one controls for telephone communication among countries, the negative effect of geographical distance on trade is reduced. Given that distance does not solely act as a proxy for transaction costs, the gravity model can be used to analyze other types of bilateral economic relationships, such as cross-border equity flows. Studies on Foreign Portfolio Investment (FDI) holdings have demonstrated that trade and equity holdings are in fact correlated, and that distance negatively affects both (Aviat and Coeurdacier, 2007). 
Although the literature which adopts gravity-type models to analyze bilateral illicit flows is small, it is nevertheless focused on a variety of forms of illicit international trade. Gravity-type models were first adopted to estimate money laundering (Walker, 1995; Walker and Unger, 2009). The share of proceeds of crime generated in country $i$ and transferred to country $j$ is influenced by the mass and 'attractiveness' of country $j$, in addition to the distance between the two countries. The mass of $j$ is measured as the per capita Gross National Product (GNP), whilst attractiveness is the sum of several weighted factors, including banking secrecy, governmental attitudes, and levels of corruption. Since data on bilateral money laundering flows are not available, the model cannot be tested empirically, which both raises doubts about its effectiveness, and impedes the statistical estimation of the attractiveness parameters (Ferwerda et al., 2013; Reuter, 2013). Recently, Ferwerda et al. (2013) tested both Walker's original model and a traditional gravity model expanded by attractiveness variables, using a subset of money laundering data, i.e. trading-based money laundering data on flows from the US to 199 other countries. ${ }^{4}$ The former 'perform[ed] badly' (Ferwerda et al., 2013, p. 3178), whereas the latter identified licit trade, distance, shared borders, and the importing country's GDP and multilateral cooperation in the fight against money laundering as factors which explain bilateral trading-based money laundering.

Wiseman and Walker (2017) recently adopted a gravity model to analyze the relationship between underground trade flows between US states and these particular states' policies on marijuana decriminalization. Underground trade flow between state $i$ and state $j$ is modeled as a function of the shadow economy value for state $j$, a vector of controls - including the demand for illicit drugs, the rate of police officers to public employees, and level of public official corruption in state $j$ - and the distance between the two states. Two dummy variables also identified whether states $i$ and $j$ allow for legal exceptions for medical marijuana. A similar approach was used by Akee et al. (2014) in order to model transnational human trafficking. The authors specifically adopted a modified gravity model that specified trafficking as a function of per capita GDP and geographical distance, and which also included country-specific legislation (i.e. prostitution laws in source and host countries, and the provision for legal amnesty to trafficked victims in the latter) in an attempt to account for push and pull forces. ${ }^{5}$ The results demonstrated that legislation prohibiting prostitution had a positive impact on trafficking in both source and destination countries, most likely due to an inelastic demand of trafficked victims. Legislation has also been shown to affect the interstate flow of crime guns: another study adopting a gravity approach looked at the interstate movement of guns recovered at crime scenes in the US, and found that differences in state gun laws impacted on the exportation of illegal guns (Kahane, 2013). The interstate flow of crime guns is also positively associated with the economic mass of the states involved - measured by the states' GDP - and inversely proportionate to their distance.

These studies suggest that a gravity approach may also be expedient for analyzing bilateral drug trade, and that the amount of drugs traded between any two given countries can similarly be modeled as a function of their size, geographical distance, and other covariates. In the case of cross-country illicit activities for example, the measurement of a country's size within previous research has varied according to the particular good or service that is being illegally exchanged. In the case of international drug trafficking, the size may be measured by the estimated illicit gross profit of the countries involved in the trade. Alternatively, the number or prevalence of drug users may be used to measure the size of a

\footnotetext{
${ }^{4}$ The attractiveness variables included: corruption; a dummy variable indicating whether a country's financial institutions are SWIFT members; governmental attitudes towards money laundering; a country's involvement in conflicts; banking secrecy; a dummy variable indicating membership of the Egmont group (i.e. a multilateral co-operation agreement to fight money laundering); financial sector size (measured as deposits); and physical and cultural distance.

${ }^{5}$ Other control variables include, among other things, shared borders, mortality rate, literacy rate, and unemployment.
} 
country's consumer market. Assuming that the drug flows are driven by economic profit, i.e. from lower-income to higher-income countries, the GDP or per capita GDP can also be used as a proxy for countries' economic mass in the case of international drug trade, although past research suggests that legal and illegal trade networks have significant differences (Boivin, 2013). In the case of the former, core countries are involved in most exchanges and largely trade with other core countries. In the case of the latter, peripheral countries in legal trade are often drug producing countries, and, as such, are more heavily involved within the drug trade, whereas core countries in legal trade are dependent on peripheral countries for their supply of plant-based drugs, such as heroin and cocaine. Consequently, many exchanges occur between different categories of countries and are directed toward the core, rather than being concentrated among core countries (Boivin, 2013).

Notwithstanding these issues pertaining to differences between legal and illegal trade, the gravity approach to heroin flows also raises some important methodological concerns. The main limitation of the gravity model is that it assumes that all observations are independent, yet 'when modelling international trade, the assumption of conditional independence is difficult to sustain even in the presence of directed country or dyad fixed effects' (Ward et al., 2013, p. 96). Country-specific exporter and importer effects are also ignored in this model, although they were found to be large and persistent over time. International commerce is also asymmetric, with a small number of countries accounting for most of the trade, which means that some countries are included several times in the data, so that the assumption that trade-flows from the same country are independent cannot be considered valid (Ward and Hoff, 2007). Moreover, the gravity model ordinarily is fitted using Ordinary Least Squares (OLS), whose estimates can be problematic in a network in which many observations are zeros (Mazur et al., 2015).

A second issue concerns the generalizability of the results beyond the timespan considered in the analyses. Most studies tend to analyze trade flows over a yearly period or over the course of a number of years; however, such data does not constitute a random sample, but, rather, includes all exchanges recorded in the period under consideration in the analyses. The relationship between trade flows and the independent variables may change over time. To address these issues, some authors suggest evaluating the explanatory power and the temporal persistence of a set of independent variables based on out-ofsample predictive performance, that estimates the validity of the model using a random sample from the database ('training set'), and predicting the values for its complement ('test set') (Ward and Hoff, 2007). This method has recently been adopted by Mazur and colleagues (2015) to identify patterns in Foreign Portfolio Investment (FPI) holdings that can be generalized across time.

Some studies have tried to overcome these aforesaid issues in relation to legal trade by incorporating relational information (e.g. alliances) into a regression framework, in conjunction with using the traditional gravity model with a series of covariates. Haim (2016) posits that we should cluster standard errors so as to adjust for dependencies in the data. Dependency is partly taken into account by linear mixed-models that incorporate both sender and receiver random effects. In this particular case, only observations with different sender or receiver countries are considered independent. Nonetheless, higher order dependencies - i.e. reciprocity, transitivity, balance, and clusterability - are not taken into account within this class of models (Mazur et al., 2015). To cite an example, transitivity captures the 'friend of a friend is a friend' logic. That is to say, if country $i$ trades with country $j$, and country $j$ trades with country $k$, then the probability of a flow of goods between $i$ and $k$ is higher than that between $i$ and a random fourth country that has no prior involvement in a trade relationship. Higher order dependencies can be taken into account by assigning each country a position in a 'social space,' based on its (unobserved) characteristics and the presence of other ties. Conditional independence between 
observations can then subsequently be assumed, given the countries' latent position within the social space (Hoff et al., 2002).

Latent position models for social networks were introduced by Hoff, Raftery and Handcock (2002), before being extended to weighted networks (Hoff, 2005; Sewell and Chen, 2016). Such models postulate the existence of a 'social space' of unobserved latent characteristics. They assume that each node has an unknown position in the social space of characteristics, and that the distance between two nodes decreases as their characteristics become more similar. They then model the probability of a connection between two nodes as a function of the distance between their latent space positions, i.e. their positions in the social space of characteristics. Consequently, nodes are conditionally independent given their positions in the social space (Hoff et al., 2002; Krivitsky and Handcock, 2008). In the case of a trade network, latent space position models take the following form:

$$
Y_{i, j} \equiv \ln \left(\operatorname{trade}_{i, j}\right)=x_{i, j} \beta+u_{i}+u_{j}+z_{i} z_{j}^{\top}+\epsilon_{i, j}
$$

where $x_{i, j}$ are fixed covariates, $\beta$ is the parameter estimates, $u_{i}$ and $u_{j}$ are the respective sender and receiver random effects, $z_{i} z_{j}^{\top}$ are the latent space positions of $i$ and $j$, and $\epsilon_{i, j}$ the residual error (Krivitsky and Handcock, 2008; Mazur et al., 2015).

Latent space position models thus enable researchers to take into consideration both edge weights and interdependencies among observations in the analysis of the generative processes and potential evolution of trade networks. Alternative approaches have been proposed, but they are either still under development (Denny et al., 2015; Desmarais and Cranmer, 2012; Wilson et al., 2015) or merely suitable for rank-order data (Krivitsky, 2012; Krivitsky and Butts, 2015). The use of Exponential Random Graph Models (ERGM) is instead suitable only in the case of binary network data, such as in the case of analyzing the network of alliances among countries (Cranmer et al., 2012).

A relatively limited range of studies (Howell, 2013; Ward et al., 2013) combine the gravity model specification with latent space model covariates in order to capture higher order dependencies in world trade networks. Observations (i.e. edge values) are assumed to be stochastically independent, in light of the country's latent positions in a $k$-dimensional social space. A similar approach is also used by Mazur et al. (2015) to analyze Foreign Portfolio Investment (FPI) holdings, whereby the investment amount is classified in terms of edge weights. In addition to latent space model covariates, the authors, in accordance with Krivitsky et al. (2009), included random sender and receiver effects. Parameter estimates were obtained through a Markov Chain Monte Carlo (MCMC) technique of Gibbs sampling over the covariates (Krivitsky and Handcock, 2008). This estimation strategy outperformed both linear models and linear mixed models that incorporate sender and receiver random effects (Mazur et al., 2015).

\section{Determinants and hypotheses}

Through utilizing the gravity model as the starting point from which to describe international trade, we postulate that the amount of traded heroin between any two given countries is a function of their size or economic mass, and their geographical distance. However, several other factors can also explain the intensity and direction of international heroin trafficking. Studies from a variety of disciplinary backgrounds are expedient, directly or indirectly, for providing insights into the geographical configuration of international drug trade flows (e.g. Kleemans and van De Bunt, 1999; Paoli and Reuter, 2008). In what was the first attempt to systematically organize knowledge on this topic, Reuter (2014) 
posited that smugglers' attempts to minimize risks and maximize profits, geographical proximity and social proximity (e.g. migration flows and common language) were the primary drivers of international drug trafficking.

According to a neoclassical approach to crime (Becker, 1968) and rational choice theorists (Barry and Hardin, 1982; Cook and Levi, 1990), individuals decide to traffic illicit drugs, or commit any other offence, to increase their own utility. That is to say, offenders are rational actors who decide to commit an offence when the gains outweigh the losses. In this respect, criminals' motivations do not differ from those who do not commit crimes, nor does their behavior necessarily require ad hoc pathological or sociological interpretations (Becker, 1968). Accordingly, illicit flows are more likely to form where profits are higher and risks are lower (Caulkins and MacCoun, 2003; Reuter, 2014). Faced with several alternatives, then, traffickers are more likely to opt for the route with the lower risk of interdiction and the higher return. Therefore, according to this perspective, the higher the economic return per unit sold, the higher the probability that any two given countries will form a trading relationship and develop an intense trafficking relationship. As a result of this, countries with large and profitable markets are more likely to establish a trading relationship. Similarly, the higher the risk of arrest or drug seizure, then the lower the quantity of heroin trafficked between any two countries. Opportunities may also drive up commission from crimes by creating a crime-prone environment (Felson and Clarke, 1998). For example, it has been shown that corruption reduces international legal trades (Anderson and Marcouiller, 2002); conversely, weak and corrupted institutions can reduce the risks for smugglers and help foster illicit drug trafficking between countries.

According to Reuter's second assumption, geographical proximity to main consumer or producer countries - e.g. Mexico for the US and Venezuela for Colombia - is a crucial risk factor for becoming a transshipment country (2014). Geographical distance is one of the key components in the gravity model of legal trade. Indeed, scholars have extensively examined the effect of distance on legal trade flows and proved that, despite technological innovations, it still has a negative effect on bilateral trade between countries (Disdier and Head, 2008). This is because geographical distance increases transport and organizational costs, and, in the case of illicit activities, increases the exposure time for the shipment, thus making it more vulnerable to the interdiction activities of law enforcement authorities. Accordingly, drug flows between countries are likely to be higher if the countries involved in the trade are geographically closer.

The third assumption outlined by Reuter (2014) is that social proximity can facilitate trafficking among countries. To illustrate this, he asserts that ethnic groups with a significant role in the import of illicit drugs in Europe (e.g. Colombians for cocaine and Albanians for heroin) are characterized by a vast migrant community in several European countries. An emergent body of research has investigated the role of migration, documenting its positive effect on bilateral legal trade (Rauch, 1999; Rauch and Trindade, 2002; Sgrignoli et al., 2015). Immigrants often maintain connections with their home country, and thus may help the host country to extend its trading relationships beyond its national borders, as migrants' informal trade networks can facilitate access to valuable information and reduce the barriers to trade (Sgrignoli et al., 2015). This factor can be even more significant in the context of international drug trafficking, where a lack of reliable information can hamper new suppliers' access to the market, especially in terms of substances like heroin and cocaine (Pacula et al., 2010).

Historical and cultural roots may also be of benefit to the trade of legal goods (Lee and Park, 2015; Rauch, 1999). Similarly, speaking the same language can be an important asset, even an advantage, for drug suppliers (Paoli and Reuter, 2008). For instance, suppliers need to come to an agreement on quantity, quality and location of the shipment. Further, they may need to deal with hostile situations 
(e.g. police investigations or the seizure of the shipment) that necessitate the business partners working together to find a common solution. Speaking the same language, then, can make negotiations easier, increase the trust between the sellers and the buyers, and reduce transaction costs (Ghemawat, 2001; Lameli et al., 2013; Sgrignoli et al., 2015). Social factors can thus make two countries closer and directly impact both legal and illegal bilateral trade. Resultantly, we expect social proximity to play a pivotal role in the trade of heroin between countries. Further, trafficking flows are expected to follow the same patterns as migration and colonial relationships. Similarly, heroin is expected to be more likely to be traded between countries whose populations speak the same language.

\section{Data and method}

\section{Dependent variable}

The study focuses on transnational heroin flows between countries. The unit of analysis is thus the dyad, i.e. any pair of countries in a weighted network of heroin trafficking involving 61 countries. The presence and weights of the edges in the heroin trade network are estimated using a three-step methodology developed by the UNODC (2015b). The first step involves identifying the countries involved in the heroin trade and the respective trading relationships between them, for the purposes of developing a binary network of cross-country heroin trafficking. The second step estimates the total quantity of heroin trafficked to Europe. Finally, the third step calculates the quantity of heroin trafficked between any pair of countries identified in the first step. That said, this section briefly summarizes the main steps of the estimation process; for a more detailed discussion of the methodology, see Annex 1 of the UNODC report (2015b, p. 55).

The first step identifies heroin flows to and within Europe based upon seizure cases. Law enforcement agencies, at times, are able to state the origin and/or the destination of the drug shipments they intercept. For instance, a seizure of heroin on the border between Serbia and Croatia which is bound for Slovenia provides evidence for two connections: one between Serbia and Croatia; and another between Croatia and Slovenia (Boivin, 2013). This type of information enables us to identify pairs of trading countries and begin to construct the transnational heroin trafficking network (UNODC, 2015b).

This study mobilises seizure cases between the periods of 2007 and 2012, involving both European countries $(\mathrm{N}=36)$ and non-European countries $(\mathrm{N}=25)$ importing from or exporting to Europe. ${ }^{6}$ The UNODC's Individual Drug Seizure (IDS) dataset - the widest available dataset on seizure casesprovides information about a series of shipments seized by law enforcement agencies; such information includes the origin, transit, destination, and weight of the intercepted drug loads. The UNODC administrates the Annual Reports Questionnaire (ARQ) to officials of the UN member states and supplements the received information with data collated from other international organizations (UNODC 2015b). Commonplace misunderstanding of the questionnaire itself, not to mention routine compiling errors, necessitate the need to scrupulously check the information reported in the dataset (Boivin, 2011). After cleaning the dataset, 10,378 different heroin exchanges were identified in relation to 187 pairs of countries. $^{7}$ Table A1 in the Appendix lists the 61 countries that form the heroin trade network under analysis.

\footnotetext{
${ }^{6}$ Countries are labeled as European according to the macro geographical regions identified by the United Nations (UNODC, 2015c).

${ }^{7}$ Heroin cannot be produced in Europe and, according to the UNODC (2015a), Afghanistan makes up a large share of the worldwide opium cultivation, and, as such, is the principal source country for illic it opiates flowing to Europe.
} 
The second step estimates the total quantity of heroin trafficked to Europe. In accordance with Paoli et al. (2009), this equates to the quantity of heroin consumed and seized in Europe. Consumption rates are obtained by multiplying the estimate of the number of heroin users in each country by their estimated annual consumption. Prevalence data provided by UNODC and EMCDDA are expedient for estimating the number of heroin users (EMCDDA, 2015b; UNODC, 2015d). Resultantly, the current study posits that European heroin users consume on average 30 grams of pure heroin per year, which is in line with previous estimates by Paoli et al. (2009), which have subsequently been validated by other studies (Kilmer et al., 2013). Seizures are then adjusted for purity so as to make estimates comparable across countries, before being added to consumption. The overall sum of seizures and consumption for all countries included in the analysis composes the estimate of the amount of heroin shipped to Europe.

Finally, the third step calculates the quantity of heroin passing through each route between pairs of countries identified in the first step. This requires: (1) determining the relative weight (\%) of each link with respect to the other links connecting the same importing country; (2) estimating the total quantity of heroin imported by each country; (3) combining these two estimates. In order to estimate the relative relevance of the dyads for any importer $\left(d r r_{i j}\right)$, the volume of the seizures between any two countries $\left(S_{i j}\right)$ is then divided by the total volume of seizures in the importing country $\left(\sum_{j=1}^{J} S_{i j}\right)$ :

$$
d r r_{i, j}=\frac{s_{i j}}{\sum_{j=1}^{J} s_{i j}}
$$

where $J$ is the total number of $j$ countries exporting cocaine to $i$. The information on seizures necessary to produce this estimate comes from the IDS dataset previously used for building the binary network. Connections that account for less than 1 per cent of the import of the receiving country are not included in the network. Setting this threshold helps to clean out of the network those connections whose relevance is marginal and highly volatile. The threshold and the geographical criterion (links to European countries) thus mark the boundaries of the heroin trafficking network.

The total imported volume - which is the sum total of consumption and seizures - is then subdivided among the different incoming links according to their relative relevance for the importing country, thus providing the final weight of every connection. Fig. 1 represents a simplified illustration of the construction of the heroin trafficking network.

This process of constructing the weighted network is not without its limitations. As aforesaid, seizures data are highly imprecise at the best of times, not to mention that UN member states submit information about relevant seizure cases on a strictly voluntary basis (Boivin 2014c). Hence, some countries may not report information to the ARQ every year, while others may even be reluctant to share information about drug seizures. Furthermore, seizures of illicit psychoactive substances, in fact, represent a relatively small percentage of the total flows between countries (Crocker et al., 2011; Miron, 2003). Consequently, a couple of large seizures are capable of causing significant fluctuations in the overall size of interceptions. In turn, some links may be particularly under- or over-represented in the IDS depending on the specific year under consideration. Three strategies are adopted to mitigate these problems.

First, the current study uses data accrued over a six-year period (2007-2012), in conjunction with examining information provided by both importing and exporting countries, for the strict purpose of mitigating the problem of under- or no reporting during some years. Assuming limited variability in reporting across this time period, this should enable the study to mitigate consequences stemming from both variations in specific country's border control and exceptional large seizures during this period. Second, focusing on European countries, which tend to provide more detailed and reliable information 
than non-European ones, should help to reduce, but not avoid completely, the risk of omitting significant trafficking routes. Third, the estimates of the size of heroin flows between any two countries does not solely depend on the relative weights of the different connections, but also on estimated internal consumption and exports.

Fig. 1. Example of the procedure performed in Step 3 of the construction of the heroin trade network
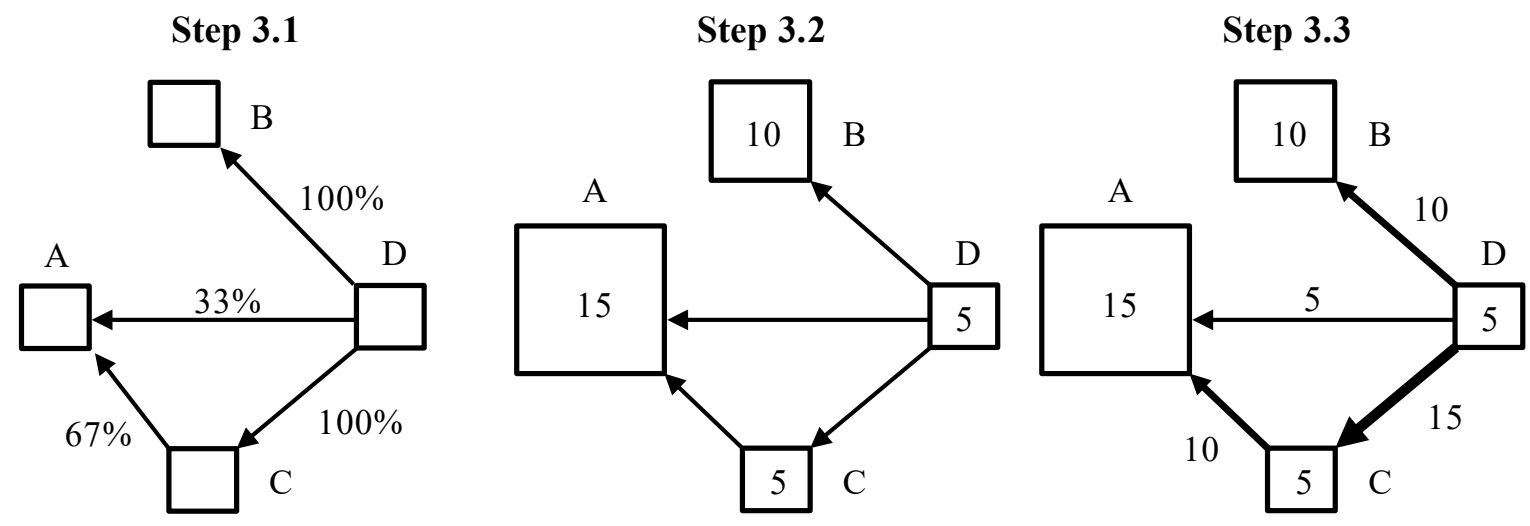

Letters and squares represent the countries included in the network; the numbers inside the squares represent countries' internal demand for heroin (i.e. consumption and seizures). Arrows represent the presence and direction of heroin flows between pairs of countries; numbers parallel to the arrows represent the proportion of heroin imported through a link (step 3.1) or the quantity of heroin exchanged by pairs of countries (step 3.3). The thickness of the arrows in step 3.3 is proportional to the heroin exchanged along the links. First, the trading relationships among countries A, B, C, and D, and the relative weight (\%) of an importer's incoming links with respect to the other incoming links of the same importer are identified. According to the IDS dataset, $33 \%$ of the heroin shipment in country A comes from country D, and the remaining amount from country C. According to the estimate in step 3.2, country A needs to import 15 tons of heroin to satisfy its internal demand; therefore, 5 tons are imported from country D (33\%) and 10 tons from country C (67\%). Similarly, country C imports only from country D (100\%), and needs to import enough heroin to satisfy its internal demand (5 tons), as well as $67 \%$ of country A's internal demand. Therefore, 15 tons are exchanged between countries $\mathrm{D}$ and $\mathrm{C}$. As regards the trading relationship between country $\mathrm{D}$ and country $\mathrm{B}$, the latter imports only from the former, and has an internal demand of 10 tons. Therefore, the estimated quantity of heroin flowing from country D to country B equals 10 tons. Finally, country D needs to import (or produce, being the first country along the trafficking route) enough heroin to satisfy its internal demand (5 tons) plus $33 \%$ of country A's internal demand ( 5 tons), $100 \%$ of country B's internal demand (10 tons), and $100 \%$ of country C's demand ( 5 tons for country C's users and 10 tons to be exported to country A).

Differences in interception effectiveness and in reporting accuracy across countries, as well as between different modes of transport in the same country also limit the potential to soundly estimate the relative weight of each link. In particular, the adding up of data deriving from both exporters and importers introduces a potential bias possibly causing an overestimation of exports for countries with high interception rates. The use of data collected from seizures reported by importing countries would soften the relevance of the first of these issues; however, due to the scarcity of information provided by some countries, this strategy would reduce the number of detectable dyads and undermine our understanding of the network.

The estimates for internal consumption in the 61 countries under analysis also raise some concerns. Whilst we assume that heroin users consume an average of 30 pure grams of heroin per year, as estimated by Paoli et al. (2009) and confirmed across other studies (Kilmer et al., 2013), overlooking national differences in the average consumption per user represents a considerable oversimplification. However, 
the available information does not allow for precise country-specific estimates. The UNODC (2015b) assumes a two-level system of heroin consumption, differentiating between Western and Eastern European countries. Although some studies have estimated per capita heroin consumption in specific countries (e.g., Gossop et al. 1997; Eisenbach Stangl 2007; Kilmer and Pacula 2009; Eisenbach Stangl and Rodigues 2012; Kilmer et al. 2013), it is simply not possible to retrieve country-specific estimates for each of the 61 countries involved in the supply of heroin to Europe. Further developments in wastewater analysis will hopefully provide new data on drug consumption to be used to estimate transnational drug flows between countries.

Descriptive analyses of the proposed heroin trafficking network are consistent with prior representations and traditional perceptions about heroin routes (EMCDDA, 2015c; UNODC 2015a, 2015b, 2014), and, moreover, appear to support the validity of the methodology adopted for constructing the trafficking network. For instance, countries at the forefront of supplying, i.e. those countries close to Afghanistan, have a large number of outgoing ties. Hence, Pakistan (out-degree=26), Turkey (22) and Bulgaria (15) are the countries with the highest out-degree centrality, thus demonstrating their role as exporters. Similarly, consumer countries such as Spain (in-degree=14), Austria (10), Germany and Denmark (8) are characterized by a high number of incoming ties, which emphasize their role as importers. The trafficking network also foregrounds the strategic role of countries such as the Netherlands as a redistribution hub for heroin coming from South-East Europe (Calderoni et al., 2015; UNODC, 2014). According to seizures data, the Netherlands is seventh on the list in terms of outgoing ties, as well as, with 3.7 tons, the largest exporter of heroin within the EU. Despite several limitations, then, the methodology employed here is nevertheless expedient for elaborating a weighted network of international heroin trafficking, although future studies should test the robustness of the results against other specifications.

\section{Independent variables}

Independent variables were selected based on the criminological and economic theories discussed in the section 'Determinants and hypotheses,' as well as on the basis of findings from previous studies on drug flows between countries (i.e. Boivin, 2014b). Table 1 lists the independent variables and their sources, whereas Table 2 provides descriptive statistics.

Countries with large and profitable markets are expected to be more likely to establish a trading relationship. Therefore, we use the number of users per country as a proxy for a respective country's size in the heroin trade, and test whether the drug flows are driven by economic profit, i.e. to countries with large consumer markets. The difference in typical trade prices between any two countries (adjusted for purity and measured in USD/kg) and per capita GDP are also included as countries' structural characteristics that might influence heroin flows between any two countries. Data on heroin users and prices were retrieved from the UNODC Annual Report Questionnaire (ARQ); data on per capita GDP were collected from the World Bank.

The presence of police forces (rate per 100,000 population) and the seizure rate (quantity of heroin seized on trade) within each country are included as nodal attribute effects, whilst their influence is tested on the number of incoming ties and the volume of imports. ${ }^{8}$ The role of criminal opportunities as facilitating drug exchanges between countries (Felson and Clarke, 1998) is tested through including terms for the level of corruption in each country, as measured by the World Bank, i.e. perceptions of the

\footnotetext{
${ }^{8}$ Seizure rate is calculated in terms of the purity-adjusted quantity of heroin seized per year (average 2009-2012) divided by average annual trade of heroin or opium.
} 
extent to which public power is exercised for public gain, including both petty and grand forms of corruption. ${ }^{9}$

Table 1. Independent variables

\begin{tabular}{|c|c|c|c|}
\hline Hypothesis & Variable & Source & Period \\
\hline \multirow[t]{3}{*}{ Profit } & Users (ln) & UNODC & $2009-2012$ \\
\hline & $\begin{array}{l}\text { Wholesale price mark- } \\
\text { ups (purity-adjusted), } \\
\text { USD/kg }\end{array}$ & $\begin{array}{l}\text { Authors' elaboration on } \\
\text { UNODC data }\end{array}$ & 2009-2012 (average) \\
\hline & GDP (per capita) & World Bank & 2009-2012 (average) \\
\hline \multirow[t]{3}{*}{ Risk of enforcement } & $\begin{array}{l}\text { Police agents, rate per } \\
100,000 \text { populations }\end{array}$ & UNODC & 2009-2012 (average) \\
\hline & Seizures, rate on trade & $\begin{array}{l}\text { Authors' elaboration on } \\
\text { UNODC data }\end{array}$ & 2009-2012 (average) \\
\hline & Control of corruption & World Bank & 2009-2012 (average) \\
\hline \multirow[t]{2}{*}{ Geographical distance } & Weighted distance (ln) & CEPII & N/A \\
\hline & Border adjacency & CEPII & N/A \\
\hline \multirow[t]{3}{*}{ Social distance } & $\begin{array}{l}\text { Migration flows (stock, } \\
\text { ln) }\end{array}$ & UNGMD & 2010 \\
\hline & $\begin{array}{l}\text { Language spoken by at } \\
\text { least } 9 \% \text { of the } \\
\text { population }\end{array}$ & CEPII & $2000-2008$ \\
\hline & Colonial relationship & CEPII & $\mathrm{N} / \mathrm{A}$ \\
\hline
\end{tabular}

The role of geographical distance is tested by including in the models two matrices of spatial proximity as relational attribute effects: one matrix measures the distance between countries, taking into consideration the actual distribution of the population of each nation (Mayer and Zignago, 2011); $;^{10}$ the other considers two countries as neighbors if they share a border. The influence of migration, language, and colonial relationship is tested by including edge covariates for migration flows among countries from the United Nations Global Migration Database (UNGMD), the presence of a language spoken by at least 9 per cent of the population in any two given countries, and any past colonial relationship between any two countries.

Table 2. Descriptive statistics of independent variables

\begin{tabular}{lllll}
\hline Nodal attribute & Min. & Max. & Mean & St. Dev. \\
\hline Users & 155 & 3150700 & 202799 & 554121 \\
$\begin{array}{l}\text { Wholesale prices (purity- } \\
\text { adjusted), USD/kg }\end{array}$ & 3906 & 474127 & 72721 & 84488 \\
$\begin{array}{l}\text { GDP (per capita) } \\
\begin{array}{l}\text { Police agents, rate per } 100,000 \\
\text { populations }\end{array}\end{array}$ & 518 & 106811 & 24704 & 24760 \\
$\begin{array}{l}\text { Seizures, rate on trade } \\
\text { Control of corruption }\end{array}$ & 0.00 & 890.33 & 341.99 & 150.93 \\
& -1.52 & 0.47 & 0.05 & 0.08 \\
\end{tabular}

\footnotetext{
${ }^{9}$ The control of corruption index ranges from -2.5 (weak control) to +2.5 (strong control). The reciprocal of the index is used in the analysis, so that higher values indicate higher corruption levels.

${ }^{10}$ The distance between countries is based on the Institute for Research on International Economy (CEPII) weighted distance, which calculates bilateral distances between the biggest cities of any two countries, and weights inter-city distances by the share of the city in the overall country's population (Mayer and Zignago, 2011).
} 


\begin{tabular}{lllll}
\hline Relational attribute & Size & Edge count & Density & Mean degree \\
\hline Weighted distance & 61 & 3660 & - & - \\
Border adjacency & 61 & 80 & 0.087 & 2.69 \\
Migration flows (stock) & 61 & 2280 & 0.623 & 44.43 \\
$\begin{array}{l}\text { Language spoken by at least 9\% } \\
\text { of the population }\end{array}$ & 61 & 109 & 0.060 & 3.61 \\
Colonial relationship & 61 & 43 & 0.046 & 1.41 \\
\hline
\end{tabular}

\section{Models estimation}

A series of gravity and latent space models are specified in order to test the effects of the independent variables on the presence of a trading relationship and the amount of heroin traded between any two countries. The natural logarithm of the amount of heroin traded is used as the response. The natural logarithm transformation is also used for the number of users, and for the matrices of migration flows and weighted distance. All nodal attribute effects refer to importing countries, whereas the characteristics of exporting countries are not included in the models, albeit with the exception of the number of users.

First, we estimate a gravity model taking the form of the linear model in Eq. (1), where $\ln \left(\operatorname{trade}_{i, j}\right)$ is the natural logarithm of heroin traded between any two countries $i$ and $j, M_{i}$ and $M_{j}$ are the respective sender and receiver economic masses, $D_{i, j}$ the distance between $i$ and $j, Z_{i, j}$ other covariates, and $\epsilon_{i, j}$ the residual error. The economic masses are proxied by the number of drug users. $Z_{i, j}$ comprise all independent variables listed in Table 1, i.e. the per capita GDP, the rate of police agents per 100,000 population, the rate of seizures on consumption, and the level of corruption in the importing countries, as well as wholesale price mark-ups, migration flows, common language, and colonial relationships between $i$ and $j$. In accordance with Hoff and Ward's approach (Hoff and Ward, 2004; Ward and Hoff, 2007), we analyze the residuals from the gravity model and we check for higher order dependencies in the data.

Second, we estimate latent space position models, adopting a two-step approach to estimate the parameters (Mazur et al., 2015). First, latent space position models are utilized in order to model the presence of a tie between any two given countries in the heroin trade network. Second, the amount of drugs traded between any two countries is modelled, provided that a trading relationship is in place. Together, the results provide information on the determinants of the heroin trade network in Europe. The analyses were performed using the 'latentnet' package (Krivitsky and Handcock, 2015, 2008) in R (R Core Team, 2015). The fixed effects are selected based on backward elimination via BIC (Mazur et al., 2015; Schwarz, 1978). Random sender and receiver effects and latent positions are also included in the models.

\section{Results and discussion}

The results of the linear model in Eq. (1) are presented in Table 3. The model uses the number of users per country as a proxy for a respective country's size to test whether the drug flows are driven to countries with large consumer markets. The number of users in the importing countries and shared borders are statistically significant, and the signs of the coefficients are positive, as expected. The estimated parameters for migration flows, common language, and colonial relationship are also positive 
and significant, indicating the influence of social proximity upon heroin trafficking. The parameter for corruption is also positive and statistically significant, suggesting an association between the level of corruption in importing countries and heroin flows. Instead, trade price mark-ups, police agents, and per capita GDP do not have any impact upon a country's tendency to trade with other countries.

Table 3. Coefficients and standard errors from the gravity model of the heroin trade network

\begin{tabular}{lrrc}
\hline & \multicolumn{2}{c}{$\boldsymbol{\beta}$} & Standard Error \\
\hline (Intercept) & -0.045 & & 0.210 \\
Users (sender, ln) & -0.007 & & 0.011 \\
Users (receiver, ln) & 0.031 & $* *$ & 0.011 \\
Weighted distance (ln) & -0.026 & & 0.016 \\
Border adjacency & 0.942 & $* * *$ & 0.116 \\
Police agents (receiver) & 0.000 & & 0.000 \\
Seizures (receiver) & -0.507 & & 0.260 \\
Corruption (receiver) & 0.090 & $*$ & 0.043 \\
Trade price mark-ups & 0.000 & $* * *$ & 0.000 \\
GDP/capita (receiver) & 0.000 & & 0.000 \\
Migration flows (ln) & 0.064 & $* * *$ & 0.007 \\
Spoken language & 0.249 & $* *$ & 0.095 \\
Colony & 0.431 & $* *$ & 0.149 \\
\hline
\end{tabular}

Residual error is 1.282 on 3708 degrees of freedom.

Since each of the 61 countries constitutive of the heroin trade network are represented several times in the dataset, both in their dual-role as importer and exporter, the residuals are likely to display a certain amount of structure. In accordance with Hoff and Ward's approach, we analyze the residuals from the gravity model with the number of users using a 'row and column effect model' that fits additive exporter and importer effects for each country (Hoff and Ward, 2004; Ward and Hoff, 2007). ${ }^{11}$ Fig. 2 shows the fitted values for these coefficients. The top left panel shows that Afghanistan, Bulgaria, Pakistan, and Turkey export more than any other countries within the heroin trade network that have similar explanatory variables. The top right panel shows the magnitude of importer residual effects. Spain and the United Arab Emirates, in particular, import more heroin than anticipated based upon the linear model specified in Eq. (1). Although not at the same levels of the network of legal international trade analyzed by Ward and Hoff (2007), the results nonetheless show that there is some degree of structure that cannot be explained by the gravity model.

\footnotetext{
${ }^{11}$ The 'row and column effects' model can be expressed as: $\hat{\epsilon}_{i, j}=a_{i}+b_{j}+\gamma_{i, j}$, where $i$ and $j$ range over the indices of the countries (Ward and Hoff, 2007).
} 
Fig. 2. Residual importer and exporter effects for each country within the heroin trade network

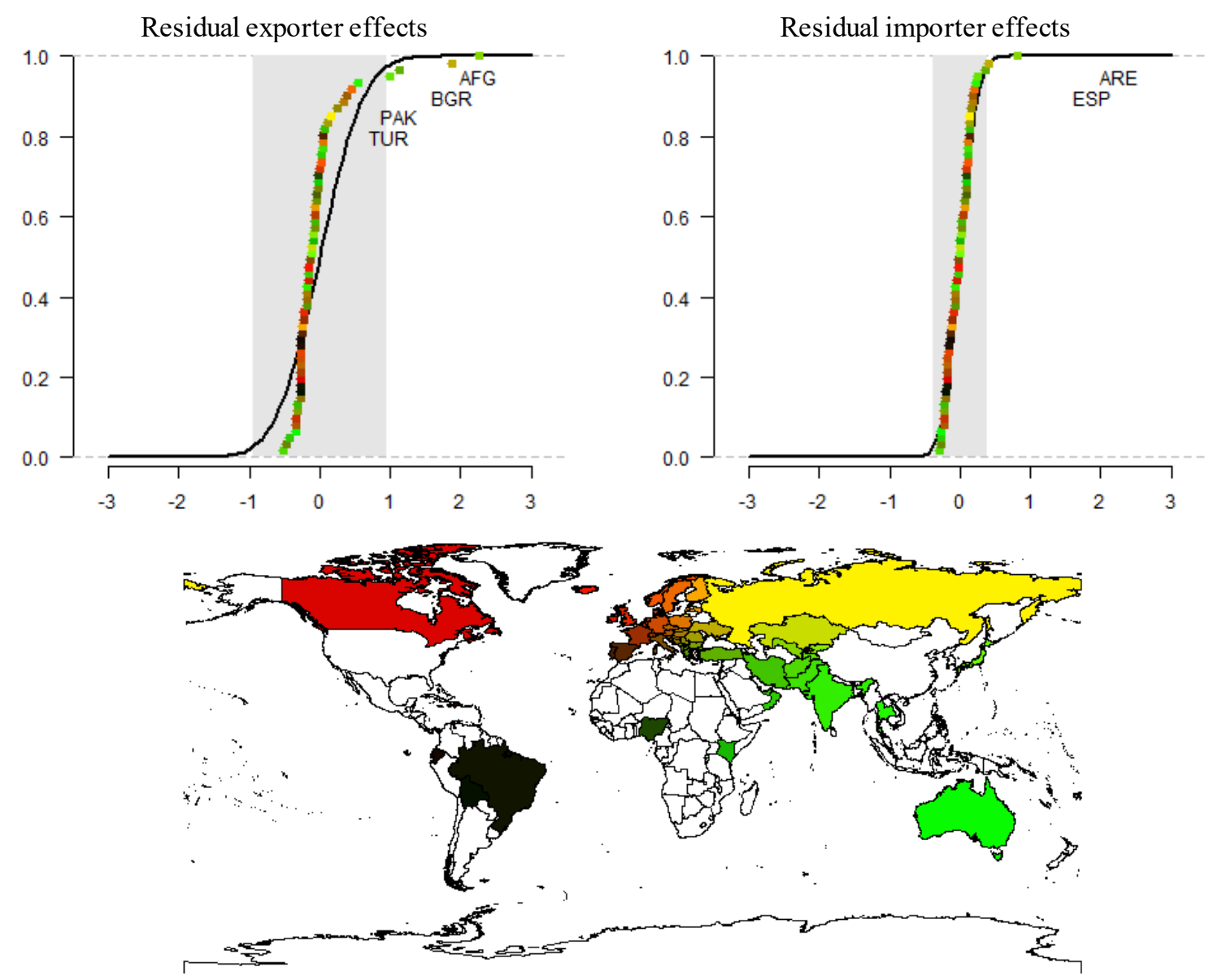

In the top panel, the exporter and importer effects are ordered from the lowest to the highest. The black line identifies the normal distribution, whereas the grey area identifies the $95 \%$ confidence interval. Colors are indexed by the map in the bottom panel, in which proximate countries have similar colors.

Higher order dependencies - i.e. reciprocity, transitivity, balance, and clusterability - are also likely to be present in relational data (Hoff et al., 2002; Hoff and Ward, 2004; Ward and Hoff, 2007). Again following Hoff and Ward's lead, we represent the residuals from the 'row and column effects' model as 'the inner product of exporter- and importer-specific vectors of latent attributes, plus a disturbance term' (2007, p. 164). The inner product captures the dependencies among the countries trading heroin to and within Europe. ${ }^{12}$ Fig. 3 displays the multiplicative effects of this, as countries in the same geographic area are represented in similar colors. If after controlling for the exporter and importer effects the trade between any two countries is higher than predicted by the gravity model, then those two countries will have similar vectors of latent attributes, and, thus, appear closer in Fig. 3. In accordance with Ward and Hoff's (2007) results for legal trade, countries in the same geographic area tend to cluster together despite the inclusion of geographical distance as a covariate in the model. Specifically, central European countries such as France, Belgium, Italy, Switzerland, the UK, and the Netherlands are clustered in the top right quadrant displaying multiplicative effects for importers, whereas post-Soviet states (Tajikistan, Kirgizstan, Uzbekistan, Russia) are clustered in the lower left quadrant. This suggests that the data displays higher-order patterns. Consequently, we must turn to latent space position models in order to

\footnotetext{
${ }^{12}$ For a systematic discussion of this method, please see Hoff (2005), and Ward and Hoff (2007).
} 
model the probability of a trading relationship between any two countries as a function of the covariates and the distance between their latent space positions, thus taking into account the interdependencies among observations.

Fig. 3. Residual multiplicative effects for exporters (b) and importers (c)

(a)

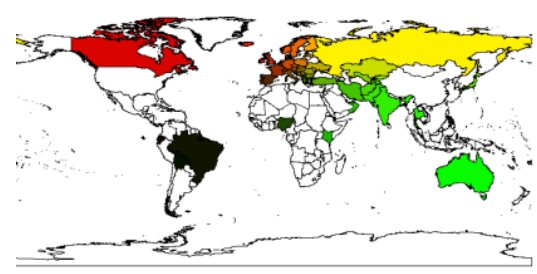

(b)

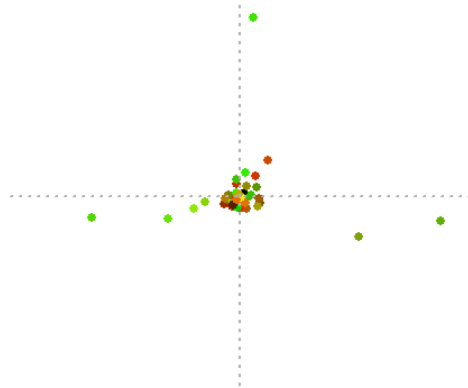

(c)

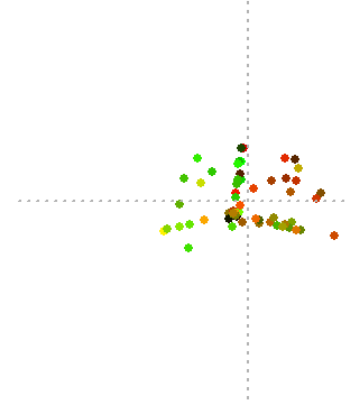

In panels (b) and (c) colors are indexed by the map in panel (a), in which proximate countries have similar colors. The map in the left panel is the same as the map in the bottom panel in Fig. 2.

The results of the latent space position models for both the presence and volume of heroin flows are presented in Table 4. Corruption and geographical proximity are shown to be among the principal factors shaping the heroin trafficking network both to and within Europe. Corruption, in particular, has an important impact on the structure of the network. That is to say, higher levels of corruption in a country increase the probability of it becoming an importer. This is because corrupted officials facilitate the smuggling of illicit goods and ensure traffickers impunity. Therefore, corruption helps to reduce nonmonetary costs by providing traffickers with protection against arrests and seizures. The other variables associated with risks do not appear to play a contributory role in the heroin trafficking network. For instance, the coefficient for the number of police agents per inhabitant is not statistically significant. Further, seizures in importing countries do not affect the formation of trade relationships among countries, nor the quantity of heroin exchanges, and were thus excluded from the final models. These results, then, do not support the hypothesis that traffickers favor countries with lower levels of enforcement and lower risks of arrest and interception of heroin shipments (Hernandez and Rudolph, 2015; Reuter and Kleiman, 1986).

Trafficking is more likely to occur, and more likely to involve large volumes of heroin, between geographically proximate countries. Coefficients are higher when modelling the presence of heroin flows; hence, geographical proximity has a bigger influence on the creation of a link between any two countries, than on the amount of heroin exchanged between the two. In contrast, sharing a border does not influence the quantity of heroin exchanged, nor the formation of new ties. The gravity model also postulates that a country's size is directly associated with outgoing and incoming heroin flows. However, when we take into account higher order dependencies, the number of users in importing and exporting countries does not appear to affect either the presence or weight of ties in the heroin trade network, as the estimates for number of users are not statistically significant. The other variables related to rewards (i.e. trade price mark-ups and per capita GDP) similarly do not appear to affect either the presence or weight of ties in the heroin trade network, and, as such, were excluded from the final models selected based on backward elimination of fixed effects via BIC.

There does appear to be evidence that social proximity does influence traffickers' decisions about transportation routes. For instance, migration flows between any two given countries are associated with 
a higher probability of forming a trafficking relationship, but not necessarily with the quantity of heroin exchanged, whereas past colonial relationships are associated with higher volumes of heroin flows. The effect of the past colonial relationship is limited to the volume of heroin flows, with the variable only affecting the amount of drug exchanged, not the presence of a tie. Once a trading relationship between any two countries is established however, then the presence of a past colonial relationship between the exporter and the importer does positively affect the quantity of heroin exchanged. The matrix that identifies the presence of a language spoken by at least 9 per cent of the population in any two countries is not associated with heroin flows, and, as such, the variable was excluded from the final models. In illicit markets, where individuals work under the constant threat of law enforcement and without the protection of any legal authority, social ties represent valuable resources for mutual trust (Paoli, 2002; Reuter, 1985). Social proximity would thus appear important in determining the direction and volume of heroin flows towards the European market.

Table 4. Coefficients and standard errors from latent space position models of the heroin trade network

\begin{tabular}{|c|c|c|c|c|c|c|}
\hline \multirow{4}{*}{$\begin{array}{l}\text { Fixed effects } \\
\text { Constant }\end{array}$} & \multicolumn{6}{|c|}{ Dependent variable } \\
\hline & \multicolumn{3}{|c|}{ Presence of heroin flows } & \multicolumn{3}{|c|}{ Volume of heroin flows } \\
\hline & \multicolumn{2}{|c|}{ Coefficient } & \multirow{2}{*}{$\begin{array}{r}\text { (Standard Error) } \\
(0.631)\end{array}$} & \multicolumn{2}{|c|}{ Coefficient } & \multirow{2}{*}{$\begin{array}{r}\text { (Standard Error } \\
(0.382)\end{array}$} \\
\hline & -0.085 & & & 2.724 & $* * *$ & \\
\hline Users (sender, ln) & 0.059 & & $(0.097)$ & -0.038 & & $(0.031)$ \\
\hline Users (receiver, $\ln$ ) & 0.156 & & $(0.117)$ & 0.086 & & $(0.058)$ \\
\hline Weighted distance (ln) & -0.598 & $* * *$ & $(0.172)$ & -0.190 & $* *$ & $(0.055)$ \\
\hline Border adjacency & 0.551 & & $(0.478)$ & 0.232 & & $(0.133)$ \\
\hline Police agents (receiver) & - & & - & 0.000 & & $(0.001)$ \\
\hline Seizures (receiver) & - & & - & - & & - \\
\hline Corruption (receiver) & 0.952 & $* * *$ & $(0.302)$ & 0.192 & & $(0.162)$ \\
\hline Trade price mark-ups & - & & - & - & & - \\
\hline GDP/capita (receiver) & - & & - & - & & - \\
\hline Migration flows (ln) & 0.183 & $* *$ & $(0.061)$ & - & & - \\
\hline Spoken language & - & & - & - & & - \\
\hline Colony & 0.657 & & $(0.621)$ & 0.360 & $*$ & $(0.175)$ \\
\hline Random effects & & Coeff & cient & & Coeff & icient \\
\hline Sender variance & & 2.3 & & & 1.3 & 38 \\
\hline Receiver variance & & 0.5 & & & 0.7 & 07 \\
\hline $\begin{array}{l}\text { Latent space position } \\
\text { variance }\end{array}$ & & 1.5 & & & 2.1 & 53 \\
\hline
\end{tabular}

Signifiance codes: ‘***’ 0.001 ; ‘**’ 0.01 ; ‘*’ 0.05 .

Finally, actor-specific random effects are included in the models, accounting for the heterogeneity of countries in regards to both incoming and outgoing ties and edge weights. Fig. A1 in the Appendix shows the plot of the latent space positions of the 61 countries involved in heroin trafficking, satisfying the Minimum Kullback-Leibler (MKL) divergence. In the model looking at the presence of heroin flows, there are several groups of countries that have similar characteristics based on their relative position in the network, but only partially overlap geographically. In the model looking at the amount of heroin exchanged, a large number of countries share similar positions in the network. Countries such as Spain, the Netherlands and Turkey, as well as Bulgaria, Germany and Austria, are seen to act as hubs in the 
trade network, thus differentiating themselves from the majority of countries involved in heroin trafficking in Europe.

Consequently, the findings of this study partly confirm those of previous research on drug trade networks and their determinants. Geographical and social proximity do operate as fertile ground for the formation of heroin flows. This is due, in part, to the fact that the presence of ethnic communities and past colonial relationships can reduce the organizational costs of illicit trades, and thus favor the formation and exploitation of illicit trading relationships among countries (Paoli and Reuter, 2008). Conversely, the ability to communicate via the same language does not have a significant effect on the likelihood of forming new trading relationships, nor does it increase the amount of heroin exchanged. Perhaps somewhat unsurprisingly, heroin traffickers tend to travel relatively short distances when moving the drug from country to country (UNODC, 2014). This can increase the time needed to move the load to its destination but, more importantly, keeps the level of sophistication required for the shipments simple, in turn, reducing the risk of interception and likelihood of arrest for traffickers.

Opportunism also appears to drive heroin flows towards countries where regulation of corruption is weak. Corruption was found to be a relevant factor in reducing legal trade (Anderson and Marcouiller, 2002) and, similarly, it is crucial in fostering the exchange of illicit goods between countries. Somewhat surprisingly, other variables originally included within the analysis do not appear to account for the pattern of the heroin trade network. For example, variables associated with risks (i.e., police agents and seizures) and rewards (i.e., price mark-ups, per capita GDP) are neither significantly associated with the presence of heroin flows, nor with the amount of heroin exchanged between countries.

The results also show that one of the main limitations of gravity models fitted using OLS - i.e. the assumption that all observations are independent - is difficult to sustain even in the case of transnational drug flows. Indeed, in our analysis we found country-specific exporter and importer effects that were ignored in these models. Latent space position models take into account interdependencies among observations, thus providing a promising modelling strategy to scholars working with weighted networks, although further research is needed to simultaneously model the presence of a tie between any two countries and the amount of drugs traded. Further research is also needed to compare different statistical models for social networks (e.g. different classes of exponential random graph models and latent space position models) and to explain any possible differences in the results.

\section{Conclusions}

This paper has modelled transnational drug flows as a directed, weighted network in order to identify the principal determinants of heroin flows both to and within Europe. Latent space position models enabled us to capture the complexity of the phenomenon by modelling both the presence and the amount of heroin flows between countries. They also afforded us to capture higher order interdependencies among observations in the analysis of bilateral illicit trade among European and non-European countries. A similar approach was utilized in order to analyze bilateral legal commerce (Howell, 2013; Ward et al., 2013) and investments (Mazur et al., 2015), and also proved its expedience for analyzing illegal smuggling of drugs across countries.

The results show that geographical and social proximity increase the likelihood of observing heroin exchanges between countries. Countries with high levels of corruption are more likely to participate in drug trafficking as transit countries, and thus have more incoming ties. Risks and rewards do not seem to play an integral role in constructing heroin trade among countries. In fact, the presence of police 
forces and their ability to seize drug shipments, the effect of price mark-ups, and the number of users in transit and destination countries have been shown to be not statistically significant.

Hence, this study provides several recommendations for policy makers and law enforcement authorities. Heroin still makes up a significant share of Europe's drug-related health and social costs (EMCDDA and EUROPOL, 2016), with the European Monitoring Centre for Drugs and Drug Addiction (EMCDDA) estimating the total drug-related public expenditure in Europe as ranging from EUR 28 to 40 billion. Moreover, prisons and police services make up about 47 per cent of public expenditure under the auspices of public order and safety (EMCDDA, 2008). This is why the disruption of cross-border illicit drug trafficking represents a key priority in the field of drug supply reduction, as outlined in the EU Drugs Strategy (2013-20). However, there is little evidence that this approach is successful in either reducing the availability of heroin or in disrupting international flows (Collins, 2014). This study puts forward alternative approaches to affect the international flows of heroin, such as strategies aimed at increasing resilience against corruption, particularly along the borders, in order to prevent countries from becoming a part of main trafficking routes in the first place.

This study also shows the potential benefits of applying social network analysis to the study of international drug trafficking and its manifold determinants. It does so by demonstrating the relevance of including edge weights in statistical models for drug flow networks, since both the effect and the significance of coefficients may vary when the amount of drug traded is considered. Future studies could seek to refine these models, both by introducing new independent variables and improving the operationalization of those already included within this analysis, as well as the heroin trafficking network itself. Further developments in statistical models for social networks may provide the possibility to jointly model the presence and amount of drug, rather than having to estimate two separate models. Furthermore, other modelling options may soon become available which allow for comparisons between different models.

Source of finances This research did not receive any specific grant from funding agencies in the public, commercial, or not-for-profit sectors.

Acknowledgments The authors thank Pavel Krivitsky and Luke Mazur (University of Wollongong), Jason Morgan (Ohio State University), Guido Consonni (Università Cattolica del Sacro Cuore) and Vera Ferluga for their help with the model specification and the 'latentnet' package in $\mathrm{R}$, and the two anonymous reviewers for their valuable comments on earlier versions of the manuscript. 


\section{References}

Akee, R., Basu, A.K., Bedi, A., Chau, N.H., 2014. Transnational Trafficking, Law Enforcement, and Victim Protection: A Middleman Trafficker's Perspective. J. Law Econ. 57, 349-386.

Anderson, J.E., Marcouiller, D., 2002. Insecurity and the Pattern of Trade: An Empirical Investigation. Rev. Econ. Stat. 84, 342-352.

Aviat, A., Coeurdacier, N., 2007. The geography of trade in goods and asset holdings. J. Int. Econ. 71, $22-51$.

Barry, B., Hardin, R., 1982. Rational Man and Irrational Society? An Introduction and Sourcebook, SAGE Publications, Thousand Oaks.

Becker, G.S., 1968. Crime and Punishment: An economic approach. J. Polit. Econ. 76, 169-217.

Boivin, R., 2014a. Macrosocial Network Analysis: The Case of Transnational Drug Trafficking, in: Masys, A.J. (Ed.), Networks and Network Analysis for Defence and Security, Lecture Notes in Social Networks. Springer, New York, pp. 49-61.

Boivin, R., 2014b. Risks, prices, and positions: A social network analysis of illegal drug trafficking in the worldeconomy. Int. J. Drug Policy 25, 235-243.

Boivin, R., 2013. Drug trafficking networks in the world economy, in: Morselli, C. (Ed.), Crime and Networks. Routledge, New York, pp. 182-194.

Boivin, R., 2011. Le monde à l'envers: Analyse de la structure du trafic transnational de drogues illicites. Université de Montréal, Montréal.

Bouchard, M., Malm, A., 2016. Social Network Analysis and Its Contribution to Research on Crime and Criminal Justice. Oxf. Handb. Online.

Caimo, A., Friel, N., 2014. Bergm: Bayesian Exponential Random Graphs in R. J. Stat. Softw. 61, 1-25.

Calderoni, F., 2014. Social network analysis of organized criminal groups, in Bruinsma, G., Weisburd, D. (Eds.), Encyclopedia of Criminology and Criminal Justice. Springer, New York, pp. 4972-4981.

Calderoni, F., Berlusconi, G., Garofalo, L., Giommoni, L., Sarno, F., 2015. The Italian mafias in the world: A systematic assessment of the mobility of criminal groups. Eur. J. Criminol. 13, 413-433.

Carrington, P.J., 2011. Crime and Social Network Analysis, in: Scott, J., Carrington, P.J. (Eds.), Sage Handbook of Social Network Analysis. SAGE Publications, Thousand Oaks, pp. 236-255.

Caulkins, J.P., MacCoun, R., 2003. Limited Rationality and the Limits of Supply Reduction. J. Drug Issues 33, 433-464.

Chandra, S., Barkell, M., 2012. What the price data tell us about heroin flows across Europe. Int. J. Comp. Appl. Crim. Justice 37, 1-13.

Chandra, S., Barkell, M., Steffen, K., 2011. Inferring Cocaine Flows across Europe: Evidence from Price Data. J. Drug Policy Anal. 4, 1-18.

Chandra, S., Joba, J., 2015. Transnational Cocaine and Heroin Flow Networks in Western Europe: A Comparison. Int. J. Drug Policy.

Chandra, S., Yu, Y.-L., Bihani, V., 2016. How MDMA flows across the USA: evidence from price data. Glob. Crime, 1-18.

Collins, J., 2014. The economics of anew global strategy, in: Collins, J. (Ed.), Ending the Drug Wars. The London School of Economics and Political Science, London, pp. 8-15.

Cook, K.S., Levi, M., 1990. The Limits of Rationality. University of Chicago Press, Chicago.

Cranmer, S.J., Desmarais, B.A., Menninga, E.J., 2012. Complex Dependencies in the Alliance Network. Confl. Manag. Peace Sci. 29, 279-313.

Crocker, C.A., Hampson, F.O., Aall, P. (Eds.), 2011. Rewiring Regional Security in a Fragmented World. United States Institute of Peace, Washington, DC.

Denny, M.J., Wilson, J.D., Cranmer, S.J., Desmarais, B.A., Bhamidi, S., 2015. gergm: Estimation and Fit Diagnostics for Generalized Exponential Random Graph Models.

Desmarais, B.A., Cranmer, S.J., 2012. Statistical inference for valued-edge networks: the generalized exponential random graph model. PLoS ONE 7.

Disdier, A.-C., Head, K., 2008. The Puzzling Persistence of the Distance Effect on Bilateral Trade. Rev. Econ. Stat. 90, 37-48.

Eisenbach Stangl, I., 2007. First Multi-City Study on Quantities and Financing of Illicit Drug Consumption QUAF1. European Centre for Social Welfare Policy and Research affiliated to the United Nations, Vienna. 
Eisenbach Stangl, I., Rodigues, R., 2012. Second multi-city study on quantities and financing of illicit drug consumption. European Centre for Social Welfare Policy and Research affiliated to the United Nations, Vienna.

EMCDDA, 2015a. European Drug Report 2015. Trends and Development. European Monitoring Centre for Drugs and Drug Addiction, Lisbon.

EMCDDA, 2015b. Data and Statistics. European Monitoring Centre for Drugs and Drug Addiction, Lisbon.

EMCDDA, 2015c. Opioid trafficking routes from Asia to Europe. European Monitoring Centre for Drugs and Drug Addiction, Lisbon.

EMCDDA, 2008. Towards a better understanding of drug-related public expenditure in Europe. European Monitoring Centre for Drugs and Drug Addiction, Lisbon.

EMCDDA, EUROPOL, 2016. EU Drug Markets Report. In-depth Analysis. European Monitoring Centre for Drugs and Drug Addiction and EUROPOL, Luxembourg.

EMCDDA, EUROPOL, 2013. EU Drug Markets Report: A strategic Analysis. European Monitoring Centre for Drugs and Drug Addiction and EUROPOL, Lisbon.

Feenstra, R.C., Markusen, J.R., Rose, A.K., 2001. Using the gravity equation to differentiate among alternative theories of trade. Can. J. Econ. 34, 430-447.

Felson, M., Clarke, R.V., 1998. Opportunity Makes the Thief: Practical theory for crime prevention. Home Office, London.

Ferwerda, J., Kattenberg, M., Chang, H.-H., Unger, B., Groot, L., Bikker, J.A., 2011. Gravity Models of Tradebased Money Laundering. Netherlands Central Bank, The Hague.

Ferwerda, J., Kattenberg, M., Chang, H.-H., Unger, B., Groot, L., Bikker, J.A., 2013. Gravity models of tradebased money laundering. Appl. Econ. 45, 3170-3182.

Ghemawat, P., 2001. Distance still matters. The hard reality of global expansion. Harv. Bus. Rev. 79, $137-147$.

Giommoni, L., Aziani, A., Berlusconi, G., 2017. How do illicit drugs move across countries? A network analysis of the heroin supply to Europe. J. Drug Issues 47, 217-240.

Gossop, M., Marsden, J., Stewart, D., Edwards, C., Lehmann, P., Wilson, A., Segar, G., 1997. The National Treatment Outcome Research Study in the United Kingdom: Six-month follow-up outcomes. Psychol. Addict. Behav. 11,324-337.

Haim, D.A., 2016. Alliance networks and trade: The effect of indirect political alliances on bilateral trade flows. J. Peace Res. 53, 472-490.

Haynie, D.L., Soller, B., 2014. Network Analysis in Criminology, in: Bruinsma, G., Weisburd, D. (Eds.), Encyclopedia of Criminology and Criminal Justice. Springer, New York, pp. 3265-3275.

Head, K., Mayer, T., 2014. Gravity Equations: Workhorse, Toolkit, and Cookbook, in: Gopinath, G., Helpman, E., Rogoff, K. (Eds.), Handbook of International Economics. Elsevier, Amsterdam, pp. 131-195.

Hernandez, D., Rudolph, A., 2015. Modern day slavery: What drives human trafficking in Europe? Eur. J. Polit. Econ. 38, 118-139.

Hoff, P.D., 2005. Bilinear mixed-effects models for dyadic data. J. Am. Stat. Assoc. 100, 286-295.

Hoff, P.D., Raftery, A.E., Handcock, M.S., 2002. Latent Space Approaches to Social Network Analysis. J. Am. Stat. Assoc. 97, 1090-1098.

Hoff, P.D., Ward, M.D., 2004. Modeling Dependencies in International Relations Networks. Polit. Anal. 12, 160 175 .

Howell, A., 2013. Is Geography "Dead" or "Destiny" in a Globalizing World? A Network Analysis and Latent Space Modeling Approach of the World Trade Network. J. Glob. Stud. 4, 126-142.

Hunter, D.R., Handcock, M.S., Butts, C.T., Goodreau, S.M., Morris, M., 2008. ergm: A Package to Fit, Simulate and Diagnose Exponential-Family Models for Networks. J. Stat. Softw. 24.

Kahane, L.H., 2013. Understanding the Interstate Export of Crime Guns: A Gravity Model Approach. Contemp. Econ. Policy 31, 618-634.

Kilmer, B., Caulkins, J.P., Pacula, R.L., Reuter, P.H., 2011. Bringing perspective to illicit markets: estimating the size of the U.S. marijuana market. Drug Alcohol Depend. 119, 153-160.

Kilmer, B., Pacula, R.L., 2009. Estimating the size of the illegal drug market: A demand-side approach. RAND Corporation, Santa Monica.

Kilmer, B., Reuter, P.H., Giommoni, L., 2015. What can be learned from cross-national comparisons of data on illegal drugs? Crime Justice 44, 227-296. 
Kilmer, B., Taylor, J., Hunt, P., McGee, P., 2013. Sizing National Heroin Markets in the EU. Insights from SelfReported Expenditures in the Czech Republic and England, in: Trautmann, F., Kilmer, B., Turnbull, P. (Eds.), Further Insights into Aspects of the EU Illicit Drugs Market. Publications Office of the European Union, Luxembourg.

Kleemans, E.R., van De Bunt, H.G., 1999. The social embeddedness of organized crime. Transnatl. Organ. Crime $5,19-36$.

Krivitsky, P.N., 2012. Exponential-family random graph models for valued networks. Electron. J. Stat. 6, 11001128.

Krivitsky, P.N., Butts, C.T., 2015. Exponential-family random graph models for rank-order relational data. Preprint.

Krivitsky, P.N., Handcock, M.S., 2015. latentnet: Latent Position and Cluster Models for Statistical Netwo rks (version 2.7.1). The Statnet Project.

Krivitsky, P.N., Handcock, M.S., 2008. Fitting Position Latent Cluster Models for Networks with latentnet. J. Stat. Softw. 24.

Krivitsky, P.N., Handcock, M.S., Raftery, A.E., Hoff, P.D., 2009. Representing degree distributions, clustering, and homophily in social networks with latent cluster random effect models. Soc. Netw. 31, 204-213.

Lameli, A., Volker Nitsch, Jens Südekum, Nikolaus Wolf, 2013. Same Same But Different: Dialects and Trade. Center for Economic Studies \& IFO Institute, Munich.

Lee, C.W., Park, S., 2015. Does Religious Similarity Matter in International Trade in Services? World Econ. 39 , 409-425.

Linnemann, H., 1966. An Econometric Study of International Trade Flows. North-Holland, Amsterdam.

Mayer, T., Zignago, S., 2011. Notes on CEPII's distances measures: The GeoDist database. Centre d'etudes prospectives et d'informations internationales, Paris.

Mazur, L., Suesse, T., Krivitsky, P.N., 2015. Investigating Foreign Portfolio Investment Holdings: Gravity Model with Social Network Analysis. National Institute for Applied Statistics Research Australia, University of Wollongong, Wollongong.

McCallum, J., 1995. National borders matter: Canada-US regional trade patterns. Am. Econ. Rev. 85, 615-623.

Miron, J.A., 2003. The Effect of Drug Prohibition on Drug Prices: Evidence from the Markets for Cocaine and Heroin. Rev. Econ. Stat. 85, 522-530.

Naylor, T., 2003. Towards a General Theory of Profit-Driven Crimes. Br. J. Criminol. 43, 81-101.

Newman, M.E.J., 2004. Analysis of weighted networks. Phys. Rev. E 70.

Pacula, R.L., Kilmer, B., Hunt, P., 2010. A framework for thinking about drug markets. RAND Corporation, Santa Monica.

Paoli, L., 2002. The paradoxes of organized crime. Crime Law Soc. Change 37, 51-97.

Paoli,L., Greenfield, V.A., Reuter,P.H., 2009. The WorldHeroin Market: Can Supply Be Cut? OxfordUniversity Press, Oxford.

Paoli, L., Reuter, P.H., 2008. Drug Trafficking and Ethnic Minorities in Western Europe. Eur. J. Criminol. 5, 1337.

Papachristos, A.V., 2014. The Network Structure of Crime. Sociol. Compass 8, 347-357.

Portes, R., Rey, H., 2005. The determinants of cross-border equity flows. J. Int. Econ. 65, 269-296.

Portes, R., Rey, H., Oh, Y., 2001. Information and capital flows: The determinants of transactions in financial assets. Eur. Econ. Rev. 45, 783-796.

Pöyhönen, P., 1963. Toward a general theory of international trade. Ekon. Samf. Tidskr. 16, 69-77.

R Core Team, 2015. R: A Language and Environment for Statistical Computing. R Foundation for Statistical Computing, Vienna.

Rauch, J.E., 1999. Networks versus markets in international trade. J. Int. Econ. 48, 7-35.

Rauch, J.E., Trindade, V., 2002. Ethnic Chinese Networks in International Trade. Rev. Econ. Stat. 84, $116-130$.

Reuter, P.H., 2013. Are estimates of the volume of money laundering either feasible or useful? in: Unger, B., van der Linde, D. (Eds.), Research Handbook on Money Laundering. Edward Elgar Publishing, Cheltenham, pp. 224-231.

Reuter, P.H., 2014. The Mobility of drug Trafficking, in: Collins, J. (Ed.), Ending the Drug Wars. The London School of Economics and Political Science, London, pp. 33-40.

Reuter, P.H., 1985. The Organization of Illegal Markets: An Economic Analysis. National Institute of Justice, Washington, DC. 
Reuter, P.H., Kleiman, M.A.R., 1986. Risks and Prices: An Economic Analysis of Drug Enforcement. Crime Justice 7, 289-340.

Savage, I.R., Deutsch, K.W., 1960. A statistical model of the gross analysis of transaction flows. Econom. J. Econom. Soc. 28, 551-572.

Schwarz, G., 1978. Estimating the Dimension of a Model. Ann. Stat. 6, 461-464.

Sewell, D.K., Chen, Y., 2016. Latent space models for dynamic networks with weighted edges. Soc. Netw. 44, 105-116.

Sgrignoli, P., Metulini, R., Schiavo, S., Riccaboni, M., 2015. The Relation between Global Migration and Trade Networks. Phys. Stat. Mech. Its Appl. 417, 245-260.

Tinbergen, J., 1962. Analysis of International Trade Flows in 42 Countries, in: Tinbergen, J. (Ed.), An Analysis of World Trade Flows in Shaping the World Economy. Twentieth Century Fund, New York, pp. 262 293.

UNODC, 2015a. World Drug Report 2015. United Nation Office on Drugs and Crime, Vienna.

UNODC, 2015b. Drug Money: The illicit proceeds of opiates trafficked on the Balkan route. United Nation Office on Drugs and Crime, Vienna.

UNODC, 2015c. Composition of macro geographical (continental) regions, geographical sub-regions, and selected economic and other groupings. United Nation Office on Drugs and Crime, Vienna.

UNODC, 2015d. UNODC statistics. United Nation Office on Drugs and Crime, Vienna.

UNODC, 2014. The illicit drug trade through South-Eastern Europe. United Nation Office on Drugs and Crime, Vienna.

van Amsterdam, J., Nutt, D., Phillips, L., van den Brink, W., 2015. European rating of drug harms. J. Psychopharmacol. (Oxf.) 29, 655-660.

Walker, J., 1995. Estimates of the Extent of Money Laundering in and through Australia. Paper prepared for the Australian Transaction Reports and Analysis Centre, John Walker Consulting Services, Queanbeyan, Australia.

Walker, J., Unger, B., 2009. Measuring Global Money Laundering: “The Walker Gravity Model.” Rev. Law Econ. $5,821-853$.

Ward, M.D., Ahlquist, J.S., Rozenas, A., 2013. Gravity's Rainbow: A Dynamic Latent Space Model for the World Trade Network. Netw. Sci. 1, 95-118.

Ward, M.D., Hoff, P.D., 2007. Persistent Patterns of International Commerce. J. Peace Res. 44, $157-175$.

Wilson, J.D., Denny, M.J., Bhamidi, S., Cranmer, S., Desmarais, B., 2015. Stochastic Weighted Graphs: Flexible Model Specification and Simulation. Preprint.

Wiseman, T., Walker, P., 2017. U.S. Interstate Underground Trade Flow: A Gravity Model Approach. Rev. Law Econ. 


\section{Appendix}

Table A1. Countries of the heroin trade network

\begin{tabular}{|c|c|c|c|}
\hline Country & Country code & Country & Country code \\
\hline Afghanistan & $\mathrm{AFG}$ & Kazakhstan & KAZ \\
\hline Albania & ALB & Kenya & KEN \\
\hline United Arab Emirates & ARE & Kyrgyzstan & KGZ \\
\hline Australia & AUS & $\begin{array}{l}\text { Kosovo under UNSCR } \\
1244\end{array}$ & KOS \\
\hline Austria & AUT & Lebanon & LBN \\
\hline Belgium & BEL & Luxembourg & LUX \\
\hline Bulgaria & BGR & Latvia & LVA \\
\hline Bahrain & BHR & Macedonia(TFYR) & MKD \\
\hline Bosnia and Herzegovina & $\mathrm{BIH}$ & Malta & MLT \\
\hline $\begin{array}{l}\text { Bolivia (Plurinational } \\
\text { State of) }\end{array}$ & $\mathrm{BOL}$ & Montenegro & MNE \\
\hline Brazil & BRA & Mauritius & MUS \\
\hline Canada & CAN & Nigeria & NGA \\
\hline Switzerland & CHE & Netherlands & NLD \\
\hline Czech Republic & CZE & Norway & NOR \\
\hline Germany & DEU & Oman & OMN \\
\hline Denmark & DNK & Pakistan & PAK \\
\hline Dominican Republic & DOM & Poland & POL \\
\hline Ecuador & ECU & Portugal & PRT \\
\hline Spain & ESP & Qatar & QAT \\
\hline Finland & FIN & Romania & ROU \\
\hline France & FRA & Russian Federation & RUS \\
\hline United Kingdom & GBR & Serbia & SRB \\
\hline Greece & GRC & Slovakia & SVK \\
\hline Croatia & HRV & Slovenia & SVN \\
\hline Hungary & HUN & Sweden & SWE \\
\hline India & IND & Thailand & THA \\
\hline Ireland & IRL & Tajikistan & TJK \\
\hline $\begin{array}{l}\text { Iran (Islamic Republic } \\
\text { of) }\end{array}$ & IRN & Turkey & TUR \\
\hline Iceland & ISL & Ukraine & UKR \\
\hline Italy & ITA & Uzbekistan & UZB \\
\hline Japan & JPN & & \\
\hline
\end{tabular}


Fig. A1. MKL latent space positions for the presence (left) and volume (right) of heroin flows

MKL latent positions for the presence of heroin flows MKL latent positions for the volume of heroin flows
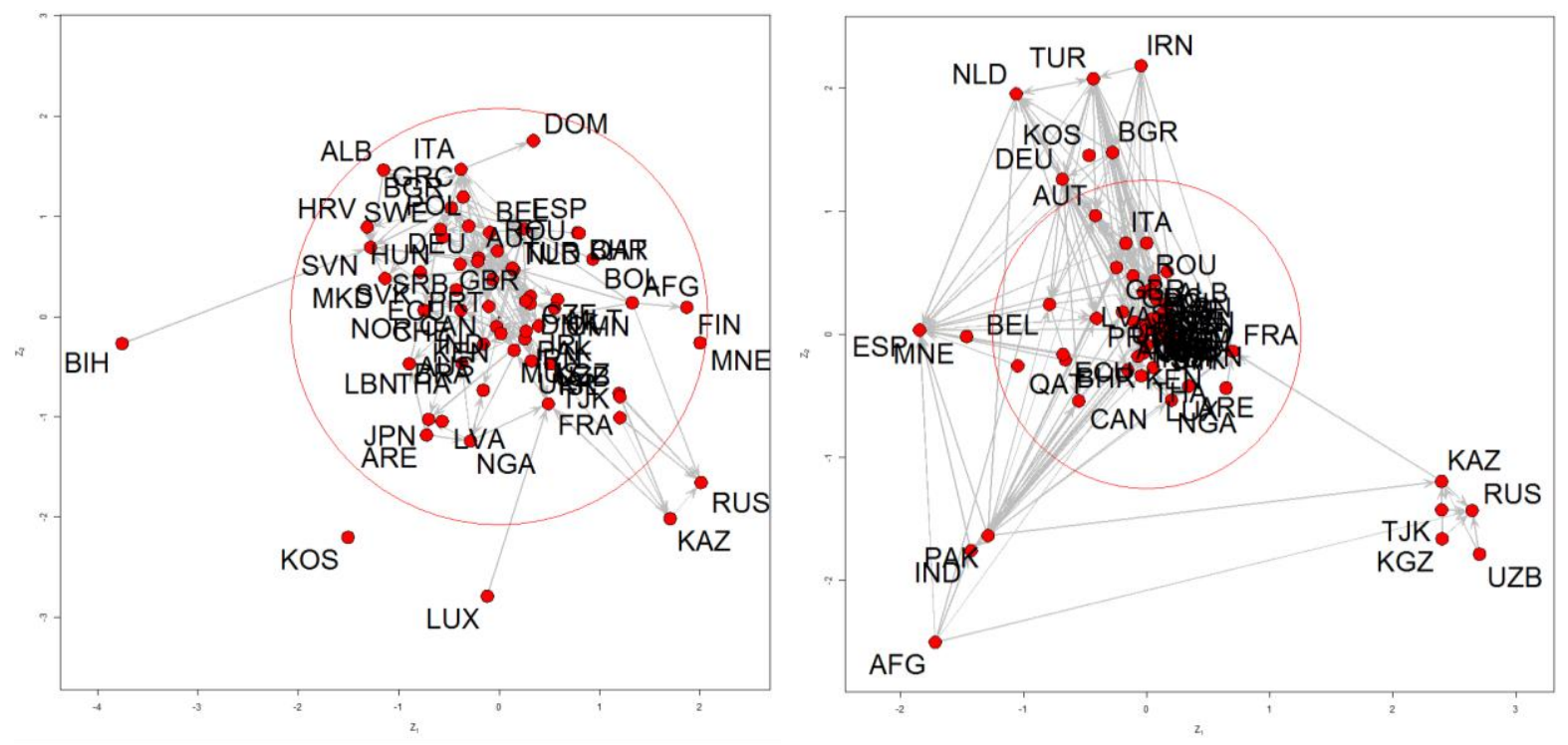